\title{
Staying in touch: how highly specialised moth pollinators track host plant phenology in unpredictable climates
}

\author{
Jonathan T. D. Finch*, Sally A. Power, Justin A. Welbergen and James M. Cook
}

\begin{abstract}
Background: For specialised pollinators, the synchrony of plant and pollinator life history is critical to the persistence of pollinator populations. This is even more critical in nursery pollination, where pollinators are obligately dependant on female host plant flowers for oviposition sites. Epicephala moths (Gracillariidae) form highly specialised nursery pollination mutualisms with Phyllanthaceae plants. Several hundred Phyllanthaceae are estimated to be exclusively pollinated by highly specific Epicephala moths, making these mutualisms an outstanding example of plant-insect coevolution. However, there have been no studies of how Epicephala moths synchronise their activity with host plant flowering or persist through periods when flowers are absent. Such knowledge is critical to understanding the ecology and evolutionary stability of these mutualisms. We surveyed multiple populations of both Breynia oblongifolia (Phyllanthaceae) and it's Epicephala pollinators for over two years to determine their phenology and modelled the environmental factors that underpin their interactions.

Results: The abundance of flowers and fruits was highly variable and strongly linked to local rainfall and photoperiod. Unlike male flowers and fruits, female flowers were present throughout the entire year, including winter. Fruit abundance was a significant predictor of adult Epicephala activity, suggesting that eggs or early instar larvae diapause within dormant female flowers and emerge as fruits mature. Searches of overwintering female flowers confirmed that many contained pollen and diapausing pollinators. We also observed diapause in Epicephala prior to pupation, finding that 12\% (9/78) of larvae emerging from fruits in the autumn entered an extended diapause for 38-48 weeks. The remaining autumn emerging larvae pupated directly without diapause, suggesting a possible bet-hedging strategy.

Conclusions: Epicephala appear to use diapause at multiple stages in their lifecycle to survive variable host plant phenology. Furthermore, moth abundance was predicted by the same environmental variables as male flowers, suggesting that moths track flowering through temperature. These adaptations may thereby mitigate against unpredictability in the timing of fruiting and flowering because of variable rainfall. It remains to be seen how widespread egg diapause and pre-pupal diapause may be within Epicephala moths, and, furthermore, to what degree these traits may have facilitated the evolution of these highly diverse mutualisms.
\end{abstract}

Keywords: Nursery pollination, Epicephala, Breynia, Diapause, Obligate pollination mutualism

*Correspondence: j.finch@westernsydney.edu.au

Hawkesbury Institute for the Environment, Western Sydney University,

Richmond, NSW, Australia 


\section{Background}

In nature, resources are often ephemeral and unpredictable. How species use ephemeral resources, such as prey, fruits or flowers, is an important question in ecology [1-3]. Flowering can be influenced by a variety of environmental factors including temperature, rainfall and photoperiod [4-6]. The timing and intensity of some environmental events, however, can be highly variable among years, making the distribution and occurrence of flowering resources unpredictable. Pollinating insects that rely on a small number of flowering species, socalled specialists or oligotrophs, may be at greater risk of extinction due to a lack of available flowers [7].

Nursery pollination mutualisms are perhaps the most specialised interactions known to occur between plants and insect pollinators $[8,9]$. In nursery pollination, insect pollinators transport pollen between the male and female flowers of a single host plant species. Along with pollen, female pollinators also deposit their eggs into female flowers. The ovules of the developing fruit then become the nursery and primary food source for the pollinator's offspring. As pollinator larvae can only usually develop within the fruits of a single host plant, adult pollinators are obligately dependant on flowers to complete their life cycles.

Many forms of nursery pollination are currently known, the most widely studied being those occurring in figs [10], Yucca [11], globeflowers [12] and some members of the Phyllanthaceae family [13]. The nursery pollination mutualisms occurring within the Phyllanthaceae or "leaf flowers" are the most recently discovered ( 20 ya) of the major mutualisms [14], and it is now believed that up to 700 species of the genera Breynia, Glochidion and Phyllanthus are pollinated exclusively by Epicephala moths (Gracillariidae), also known as leaf flower moths [15-17]. The nursery mutualisms occurring between Epicephala moths and the leaf flowers are believed to have evolved once in Asia around 23 mya before rapidly diversifying and spreading across Asia, Oceania and the Neotropics $[15,16]$. As such, these interactions are perhaps one of our most outstanding examples of plant-insect coevolution.

In nursery pollination, the synchrony of plant and pollinator life history is critical to the persistence of pollinator populations and the stability of the mutualism [18]. Within plants that use nursery pollination, there is a broad spectrum of flowering activity. Plants in the tropics can flower continuously or near continuously [18-20], whilst those in the sub-tropics and temperate regions may flower as little as once per year [21, 22]. Meanwhile, desert-dwelling Yucca species may not flower for several years at a time [11]. In many tropical fig species, individual trees flower asynchronously throughout the year, resulting in continuous year round flowering at the population level $[18,23-25]$. Indeed, the continuous flowering of tropical fig trees is critical to prevent local fig wasp extinction, as a constant supply of syconia is required to maintain stable pollinator populations $[18,23,26]$. In temperate fig trees, where flowering only occurs during the spring and summer, fig wasps overwinter in "dormant" figs and emerge the following spring [22]. As such, an important question is how are pollinator populations maintained in leaf flower nursery mutualisms, where flowering often occurs in discrete episodes and not continuously throughout the year?

Populations of pollinators in nursery mutualisms have rarely been surveyed [18]. From the few available observations, it would seem that Epicephala abundance peaks following periods of host plant fruiting [19-21]. This makes intuitive sense, given that Epicephala larvae develop by feeding on growing fruits. However, moths that pollinate plants with discrete and seasonal flowering and fruiting times cannot rely on a continuous supply of receptive female flowers to maintain their population. It is therefore likely that they have evolved mechanisms to cope with large gaps in time between fruiting and flowering. Many moths, including at least one species of Epicephala, are known to undergo diapause at the egg or pre-pupal stages as a mechanism for bridging the time between fruiting and flowering [21, 27-29]. In the Yuccayucca moth mutualisms, moths can remain in pre-pupal diapause for up to 4 years [11]. It seems likely, therefore, that Epicephala moths may use some form of diapause during these flowering-fruiting gaps.

If diapause does occur in Epicephala moths, then we should expect that it is induced and broken by the same environmental factors that influence flowering. This is because many species of Lepidoptera are known to be phenologically synchronised with their host plants via climate cues, such as temperature [30-34]. To date there have been no studies of how Epicephala moths synchronise their lifecycle with those of their host plants, or the environmental factors that influence these interactions.

We set out to determine the annual activity of Epicephala moth pollinators on their obligate host plant, Breynia oblongifolia [35, 36]. Breynia oblongifolia is generally regarded to flower and fruit throughout the austral spring, summer, and autumn (September to May), meaning that Epicephala moths are likely to experience a lack of available flowers during the winter months. However, it is unknown how these Epicephala moth populations persist through periods of time in which flowers are absent. We surveyed both pollinators and host plants for more than two years to determine their phenology. We hypothesized that because of the obligate dependence of Epicephala moths on B. oblongifolia fruits and 
flowers, moth abundance would closely track flowering phenology.

Rainfall in Australia can be highly variable between years [37-39]. As such, many species of Australian plant are known to fruit and flower in response to variation in rainfall and photoperiod $[4,5]$. We modelled the environmental factors that drive plant and pollinator phenology, predicting that the abundance of adult moths and flowers would be best predicted by rainfall and photoperiod. Then, using our newly gained knowledge of moth and host plant phenology, we looked for evidence of diapause at both the egg and pre-pupal stages. In undertaking this study, we sought to understand how highly host-specific pollinators track host plant phenology and maintain their populations over time.

\section{Methods}

\section{Study species}

Breynia oblongifolia occurs along the east coast of Australia from southern New South Wales to northern Queensland [40]. Mature plants are generally 1-3 m tall and bear unisexual male and female flowers that emerge from the leaf axils (Fig. 1). In male flowers, the stamens are almost entirely enclosed by fused sepals, with only a narrow aperture at the apex allowing access to pollinators. B. oblongifolia is known to be pollinated by at least two closely related species of Epicephala moth [35, 36]. Many species of Epicephala have been described from
Australia. However, the original species descriptions often lack information on genital morphology, which is now considered essential for their identification [41, 42]. As such, the taxonomic identity of the two Epicephala species present on B. oblongifolia is currently unknown and they are referred to as Epicephala sp. A and Epicephala sp. B. At the time of pollination, female moths oviposit eggs into female flowers. Epicephala larvae feed on the developing ovules with a single larva consuming around half the seeds in each fruit [35, 36]. Epicephala moths emerge from mature fruits as larvae and pupate on the foliage or leaf litter. However, lifecycle details of these highly specific pollinators are largely unknown.

Breynia oblongifolia is a non-protected plant species in New South Wales under the Biodiversity Conservation act of 2016. The identification and collection of all plant material was made by JF on land owned and managed by Western Sydney University. No specific collection permissions were required.

\section{Flowering and fruiting phenology}

To determine the occurrence and environmental drivers of fruiting and flowering, we recorded the reproductive phenology of four populations of B. oblongifolia at two coastal and two inland sites in NSW, Australia: Richmond, Shellharbour, Shoal Bay and Millfield (Table 1). To ensure the independence of environmental effects between sites, we chose four populations that were at
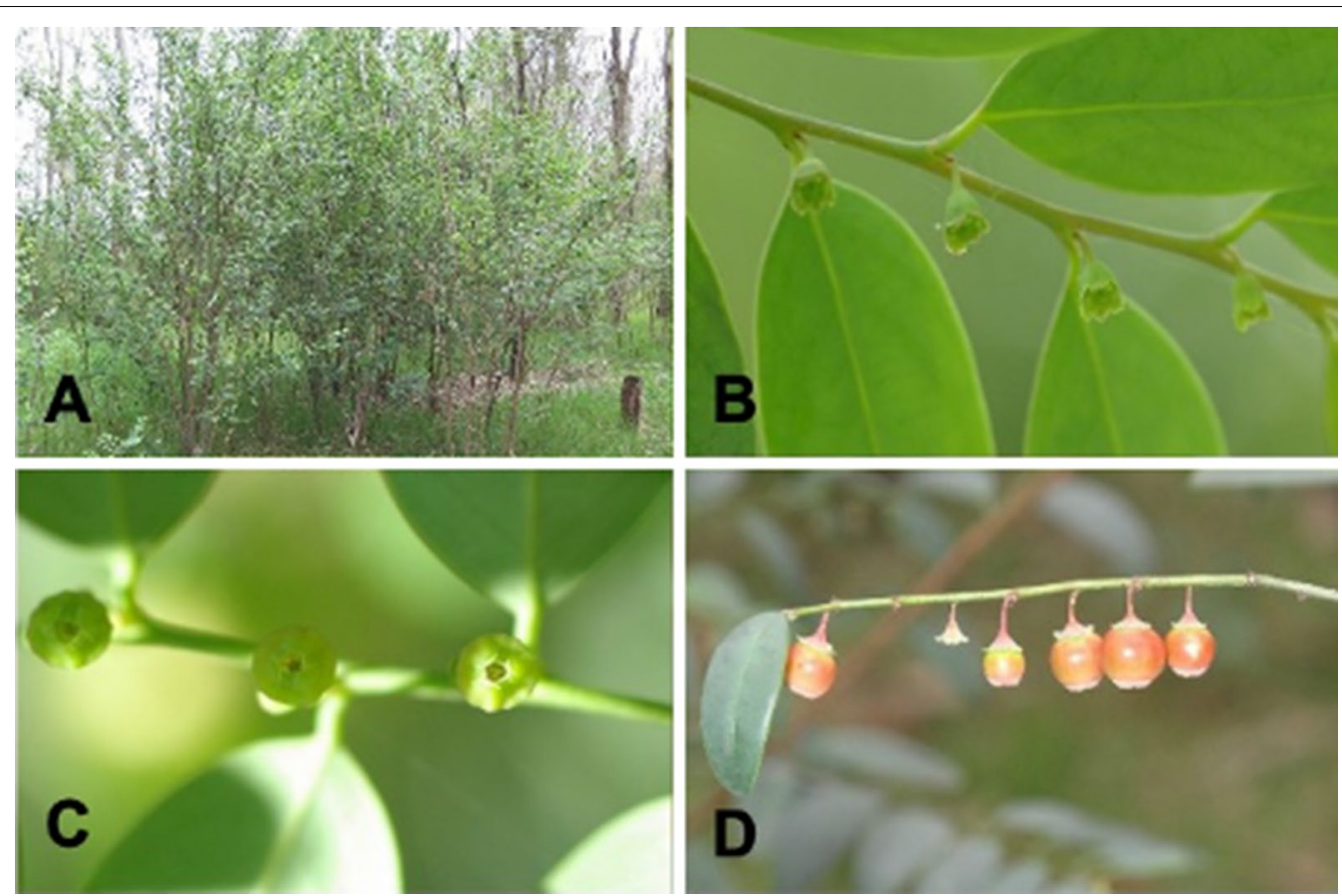

Fig. 1 Breynia oblongifolia. Mature plants A female flowers, B female flowers, C male flowers, D mature and developing fruits. All photographs by JF 
Table 1 Sampling locations and Australian Bureau of Meteorology (BOM) weather stations used for data analysis

\begin{tabular}{llll}
\hline & Grid reference & BOM Weather Station & $\begin{array}{c}\text { Distance to } \\
\text { station (km) }\end{array}$ \\
\hline Millfield (MF) & $-32.8996,151.2467$ & Pokolbin (061327) & 6.2 \\
Richmond (RC) & $-33.6194,150.7378$ & Richmond (067021) & 1.8 \\
Shoal Bay (SB) & $-32.7176,152.1673$ & Nelson Bay (061054) & 1.3 \\
Shellharbour (SH) & $-34.5945,150.8984$ & Albion Park (068241) & 3.1 \\
\hline
\end{tabular}

least $90 \mathrm{~km}$ apart. All four populations were situated in Eucalyptus-dominated woodlands, where B. oblongifolia occurs as a component of the understory and had at least 50 flowering plants. Populations at Richmond were surveyed every 2-4 weeks between September 2015 and April 2018. Other populations were surveyed at intervals of approximately 30 days between November 2016 and November 2017. At each site 20 plants were chosen by walking along a pre-determined transect line, either a road or footpath, and choosing the nearest plant $>1 \mathrm{~m}$ in height every $10 \mathrm{~m}$. Four branches, approximately $30 \mathrm{~cm}$ in length, were selected on each plant and marked for monitoring by repeat surveys. On each subsequent visit, the number of male flowers, female flowers, developing fruits $(<5 \mathrm{~mm}$ diameter) and mature fruits $(>5 \mathrm{~mm}$ diameter) were counted on each branch (Fig. 1). In total we conducted 70 surveys of flowering phenology across the four sites: 34 at Richmond and 12 at each of the other three sites. We assessed a total of 100,038 female flowers, 32,473 male flowers, 13,889 developing flowers and 12,098 mature fruits.

All statistical analyses were conducted in R Studio (v1.0.153) [43], using R (V. 1.1.414) [44]. Significance was set at $\alpha<0.05$. We obtained all temperature and rainfall data from the Australian Bureau of Meteorology (Bureau of Meteorology, 2018) using the closest available weather station $(<7 \mathrm{~km})$ at each sampling location (Table 1) to test for associations with flowering and fruiting.. Environmental variables included the sum of precipitation in the previous 14, 15-28 and 28-42 days and the sum of all rainfall across 42 days prior to each phenology observation. In addition, we calculated the average daily minimum and maximum temperatures over the 14 days prior to each phenology observation. Photoperiod is an important factor for the phenology of many Australian plants $[4,5,46]$. This was therefore included in our analysis as the duration of daylight hours on the day of observation, to the nearest minute, which we obtained from www. timeanddate.com for Sydney, NSW.

We used negative binomial generalised linear mixed models (GLMM) to determine the degree to which environmental (climate, daylength) variables influence flowering phenology, whilst controlling for the effects of site and plant. Negative binomial models are useful for modelling count data, such as ours, where a large proportion of "true" zero values results in high variance and overdispersion [47]. We constructed separate negative binomial GLMMs for the number of male, female, developing and mature fruits using the "glmer.nb" function in Lme4 library (v1.1-15) [48], specifying a random intercept and slope for each site and plant. To determine the most parsimonious combinations of environmental variables on the number of male flowers, female flowers, developing fruits and mature fruits we used the "dredge" function in the MuMIn library [49] to perform model selection. For each reproductive structure (i.e., fruits and flowers), we created a negative binomial model containing all the independent environmental variables. Models were fitted using maximum likelihood. Where the most parsimonious model identified by dredge included environmental variables that were likely to be highly correlated (i.e., maximum, and minimum average daily temperature), we created separate models for each variable and compared them using likelihood ratio tests $[50,51]$, preferring the model with the lowest AICc score. To check our assumption of over-dispersion we created an alternative GLMM using Poisson regression that does not have an extra parameter for modelling over-dispersion and compared the two models using a likelihood ratio test. For each reproductive structure, negative binomial regression models performed significantly better than poison regression models $(\mathrm{p}<0.0001)$ supporting our assumption of over-dispersion in the data.

\section{Pollinator phenology}

We conducted surveys of Epicephala moths between one and four times per week at the Richmond field site only from $13 / 11 / 2017$ to $01 / 04 / 2018$. Multiple surveys per week were conducted during periods of high Epicephala activity ( $>4$ individuals observed on the first night of observation), otherwise surveys occurred once per week. Epicephala moth activity was observed shortly after sunset when the moths became active. Surveys were conducted by continuously walking along two perpendicular boardwalks forming an " $\mathrm{X}$ " shaped transect approximately $100 \mathrm{~m}$ in total length within the 
woodland. During surveys we counted the number of Epicephala moths observed on all plants in the transect over a period of $1 \mathrm{~h}$ using a white LED head torch. Although white lights were found to disturb pollination behaviours [35], using them gave a larger field of view and better chances of detecting Epicephala than red lights. No attempt was made to determine which Epicephala species were present, as this requires destructive abdominal dissections [35].

We used negative binomial regression to model the abundance of Epicephala moth species at the Richmond site over time. To do this, we calculated the mean number of Epicephala observed per night for each week by averaging counts of Epicephala across all the observations for each week (1-4 observations) from $13 / 11 / 2017$ to $01 / 04 / 2018$. For each week, we estimated the sum of male flowers, female flowers, developing fruits and mature fruits at the time of Epicephala moth observations using our phenological data. Pearson's correlation coefficient tests showed that the mean abundance of Epicephala moths was significantly correlated with the sum of the number of male flowers, female flowers, developing fruits and mature fruits at the time of each pollinator observation (all $|\mathrm{p}|<0.05$ ). As such, we initially modelled Epicephala abundance as a function of the sum of male flowers, female flowers, developing and mature fruits using negative binomial regression in MASS package [52]. Although all four phenological variables correlated with Epicephala abundance, only the number of mature fruits was found to have a significant relationship $(\mathrm{p}<0.05)$ with the mean number of pollinators observed. The sum of male flowers, female flowers and developing fruits was thereafter excluded from our model.

We then extended our model of Epicephala abundance by adding the variables that drive fruit production, specifically rainfall, temperature, and photoperiod. To do this we constructed a range of environmental variables to include in our extended model for each weekly average count of Epicephala moths. For rainfall we calculated the total rainfall $(\mathrm{mm})$ in cumulative weekly intervals $(0-7,7-14,14-21,21-28$ and $0-28$ days) prior to each week of observations. For temperature, we calculated the sum of the minimum and maximum daily temperatures, over the same intervals as rainfall, prior to each week of observations. As photoperiod was found to be a significant predictor of the number of female flowers and developing and mature fruits, we also looked for associations between photoperiod and Epicephala abundance. To determine the most appropriate timescale for the environmental variables (i.e., 0-7, 7-14 days) we again used the "dredge" function in the MuMIn library [49] to perform model selection. We chose the model with the lowest AICc run for inclusion in our final model. The log likelihood of the alternative Poisson regression model was significantly lower than the negative binomial regression model $\left(x^{2}=392.80, p=0.007\right)$, again supporting our assumption of over-dispersion in the moth abundance data.

\section{Winter flower surveys}

The results of our phenology surveys showed that female flowers were retained over the winter period and began developing into fruits before the appearance of male flowers or moth pollinators (Fig. 3). We therefore assessed whether the female flowers present on $B$. oblongifolia over the winter period had previously been pollinated. In the late winter of 2017, we collected ten female flowers from each of $15 \mathrm{~B}$. oblongifolia bushes at Richmond. Flowers were selected haphazardly from separate branches on each plant. Flowers were taken back to the laboratory and dissected under a Leica EZ4 Stereo Microscope (Leica Microsystems, Wetzlar, Germany) to determine the number of pollen grains per flower and if any insects were present in the flowers. We used a Welch's t-test to determine if there was a difference in the number of pollen grains in flowers with and without larval feeding damage. We tested for a difference among plants in the number of pollen grains per flower using a one-way ANOVA using the $\mathrm{R}$ stats package.

\section{Pre-pupal diapause}

The results of our winter flower surveys suggested that Epicephala likely diapause as small eggs or young larvae in female $B$. oblongifolia flowers. However, we were also interested in determining if Epicephala moths may also diapause between the final larval instar and adult life history stages, as seen in Yucca moths. We collected 263 fruits from two successive crops at the Richmond site in the spring (November) $(\mathrm{n}=115)$ and autumn of 2019 (April) $(\mathrm{n}=148)$. One to ten fruits were collected haphazardly from $\sim 15$ adult $B$. oblongifolia plants. Fruits were placed individually in plastic emergence pots [36]. The pots were left outside in a shaded position to mimic ambient environmental conditions and checked at 1-2 week intervals. The type of insect, date of larval emergence and date of adult eclosion were recorded for all insects that emerged from the collected fruits. Where no insects emerged within ten weeks of collection, fruits were dissected and checked to see if they had previously contained insects. Collected Epicephala moths were identified by genital dissection [35]. 


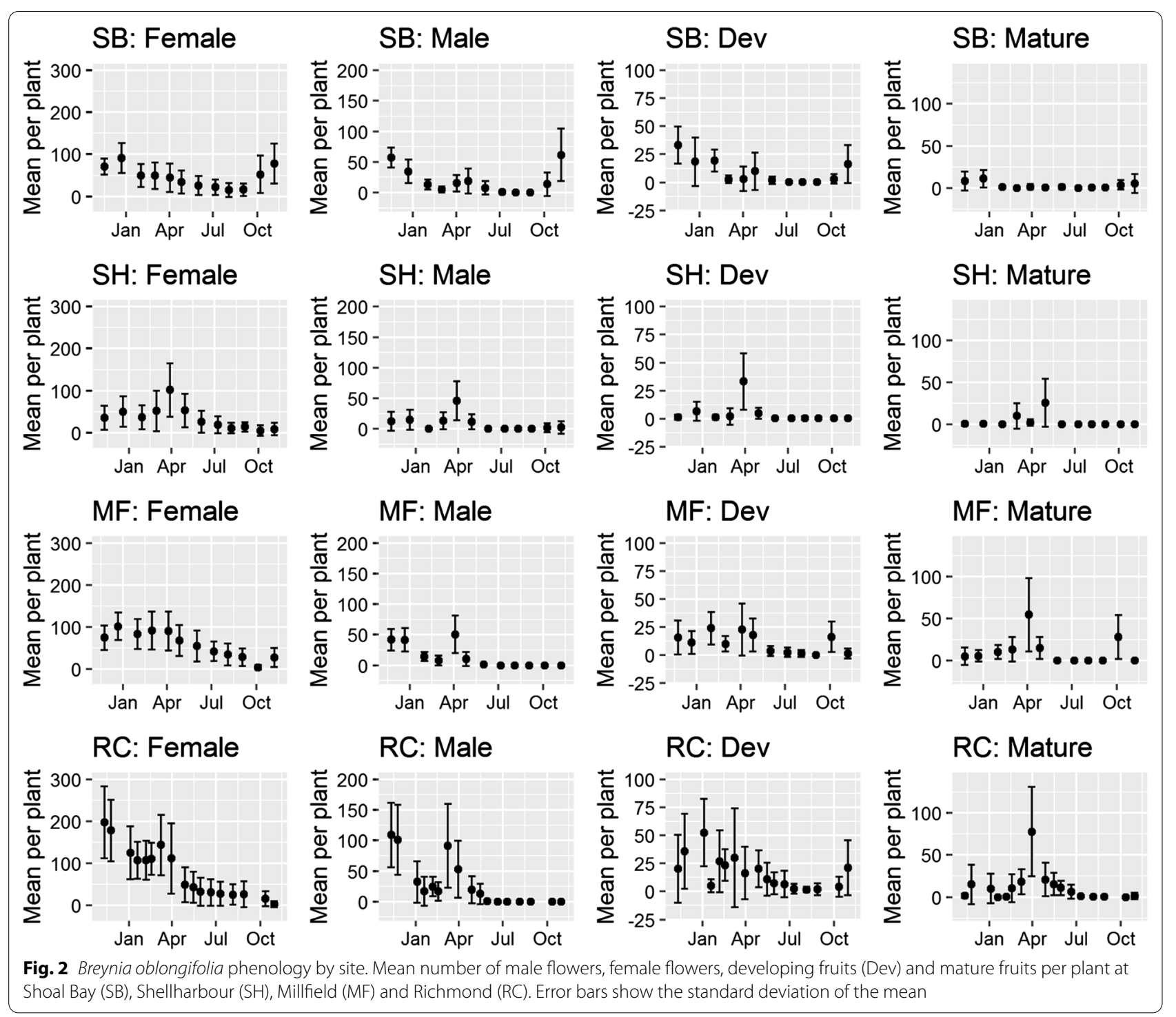

\section{Results}

\section{Flowering and fruiting phenology}

Female flowers were generally present throughout the year, peaking in abundance during the spring or late summer and declining during winter to low but stable levels (Fig. 2). Interestingly, female flowers were retained on the plants even under periods of drought. For example, in the late winter and early spring of 2017 (July-September) Breynia oblongifolia plants at the Richmond site experienced a prolonged spell of unusually dry weather (Additional file 1). During this period, the whole population showed signs of water stress including leaf rolling and leaf abscission. However, many of the plants retained a large proportion of their female flowers, even when they were heavily defoliated. Both the sum of precipitation over the past 42 days $(\mathrm{p}<0.0001)$ and photoperiod $(\mathrm{p}<0.0001)$ were significant predictors of the number of female flowers in our best performing model (Table 2).

Male flowers were most abundant during the spring and summer but declined rapidly in periods of particularly hot and dry weather (Jan-Feb) and were entirely absent during the winter months (May-August) (Figs. 2, 3 ). As with female flowers, the sum of precipitation over the past 42 days was a strong predictor of the number of male flowers $(p<0.0001)$. However, in contrast to female flowers, the average minimum temperature $(\mathrm{p}<0.0001)$ was the best predictor of the number of male flowers across the four sites (Table 3).

Breynia oblongifolia plants usually produced 1-2 fruit crops per year and each crop lasted for 1-3 months. 
Table 2 GLMM coefficients for relationships between environmental variables and flowering and fruiting phenology in Breynia oblongifolia at the Richmond, Shellharbour, Shoal Bay and Millfield sampling sites.

\begin{tabular}{|c|c|c|c|c|}
\hline & $\beta$ & $S E$ & $z$ & $p$ \\
\hline \multicolumn{5}{|l|}{ Female flowers } \\
\hline Intercept & 3.7 & 0.182 & 20.47 & $<0.0001$ \\
\hline Rainfall ${ }^{\mathrm{a}}$ & 0.23 & 0.029 & 7.97 & $<0.0001$ \\
\hline Daylight hours ${ }^{\mathrm{b}}$ & 0.58 & 0.027 & 21.22 & $<0.0001$ \\
\hline \multicolumn{5}{|l|}{ Male Flowers } \\
\hline Intercept & 2.06 & 0.242 & 8.52 & $<0.0001$ \\
\hline Rainfalla & 0.70 & 0.071 & 9.88 & $<0.0001$ \\
\hline Minimum Temp ${ }^{c}$ & 1.27 & 0.061 & 20.58 & $<0.0001$ \\
\hline \multicolumn{5}{|l|}{ Developing Fruits } \\
\hline Intercept & 1.65 & 0.33 & 4.88 & $<0.0001$ \\
\hline Rainfalla & 0.50 & 0.050 & 10.08 & $<0.0001$ \\
\hline Daylight hours ${ }^{\mathrm{b}}$ & 0.60 & 0.045 & 13.41 & $<0.0001$ \\
\hline \multicolumn{5}{|l|}{ Mature fruits } \\
\hline Intercept & 1.73 & 0.289 & 5.99 & $<0.0001$ \\
\hline Rainfall ${ }^{\mathrm{a}}$ & 0.65 & 0.08 & 7.33 & $<0.0001$ \\
\hline Daylight hours ${ }^{\mathrm{b}}$ & 0.16 & 0.067 & 2.46 & 0.0136 \\
\hline
\end{tabular}

${ }^{\text {a }}$ Sum of precipitation over the past 42 days

${ }^{b}$ Photoperiod day on the day of observation

' Sum of daily minimum temperature over the 14-21 days prior to each phenology observation

When combining across all sites, developing and mature fruits were present on plants throughout most of the year (July to May: Fig. 2) but there was considerable variation in fruit production among sites, even at the same time of year (Fig. 2). This is most likely because of differences in rainfall that varied among the four sites (Additional file 1). Fruit production did not usually occur during the hottest (Jan-Feb) and coldest parts of year (June and July), although there was some fruiting recorded in early July (mid-winter) at the Richmond site (Fig. 3). Interestingly, at this time Epicephala moths were not active (Fig. 3) and male flowers were also absent. Like female flowers, the number of developing fruits was best predicted by the sum of precipitation over the past 42 days $(\mathrm{p}<0.0001)$ and photoperiod $(\mathrm{p}<0.0001)$ (Table 2). Similarly, the abundance of mature fruits was best predicted by the sum of the precipitation over the past 42 days $(\mathrm{p}<0.0001)$ and photoperiod $(\mathrm{p}=0.0136)($ Table 2$)$.

\section{Pollinator phenology}

Epicephala moth activity at the Richmond site varied widely over our 75 -week observation period. Adults were active at the site for periods of 1-2 months in springearly summer and then again in late summer-autumn period but were absent or undetected during the winter months (Fig. 3). In both 2017 and 2018, Epicephala were scarcely recorded for up to 3 months during midsummer but quickly became very abundant again in late summer, with up to 42 individuals being recorded in a single hour-long observation period. Both the total number of mature fruits $(p<0.01)$ and the sum of minimum daily temperatures 14-21 days prior to each observation $(\mathrm{p}<0.01)$ were significantly related to the abundance of Epicephala adults (Table 3). Rainfall was, however, not related to moth abundance ( $\mathrm{p}>0.05)$.

\section{Winter flower surveys}

Many overwintering female flowers contained pollen and evidence of overwintering pollinator eggs or small larvae (Fig. 4). Of 150 inspected flowers, 118 had pollen grains on the surface of the stigma with an average of $10.9(\mathrm{SD}=5.68)$ grains per flower. There was no significant difference among plants in the number of pollen grains per flower $\left(F_{1,148}=3.75, p>0.05\right)$. Of the 150 flowers collected, 86 showed scars in the tissue of the ovary wall consistent with boring damage by Epicephala [36] and 47 contained at least one Epicephala egg or egg case (Fig. 4). These scarred flowers had between 1 and 4 scars $($ mean $=1.54, \mathrm{SD}=0.78)$ visible per flower. It was not possible to determine if these marks were attributable to multiple individuals or multiple boring attempts by the same individual. There was no difference in the number of pollen grains present in flowers with or without larval scarring $(\mathrm{t}=-0.64, \mathrm{df}=130.9, \mathrm{p}<0.520)$.

\section{Pre-pupal diapause}

Of the 263 collected fruits, 129 contained no insects, 52 contained evidence of feeding damage but no insects (i.e., insects emerged before fruit collection), 4 contained non-Epicephala insects and 78 contained Epicephala larvae. Of the 78 Epicephala larvae that emerged from fruits in the spring and autumn crops, 69 (88\%) pupated and eclosed as adults within 5 weeks with a mean time of emergence to adult eclosion of 3.6 weeks. Nine Epicephala (9/78) remained as larvae for between 37 and 48 weeks, successfully pupating and eclosing to adults from 9 months to nearly one full year after they emerged from fruits (Fig. 5). All long diapausing moths were from the autumn crop. Five were male Epicephala sp. B and the remaining four were an equal proportion of male and female Epicephala sp. A. Only 13 Epicephala were collected from the spring crop, all of which pupated within 5 weeks of emergence.

\section{Discussion}

Epicephala moths appear to use diapause at multiple stages in their lifecycle in order to deal with variable flowering phenology (Fig. 6). The close association 

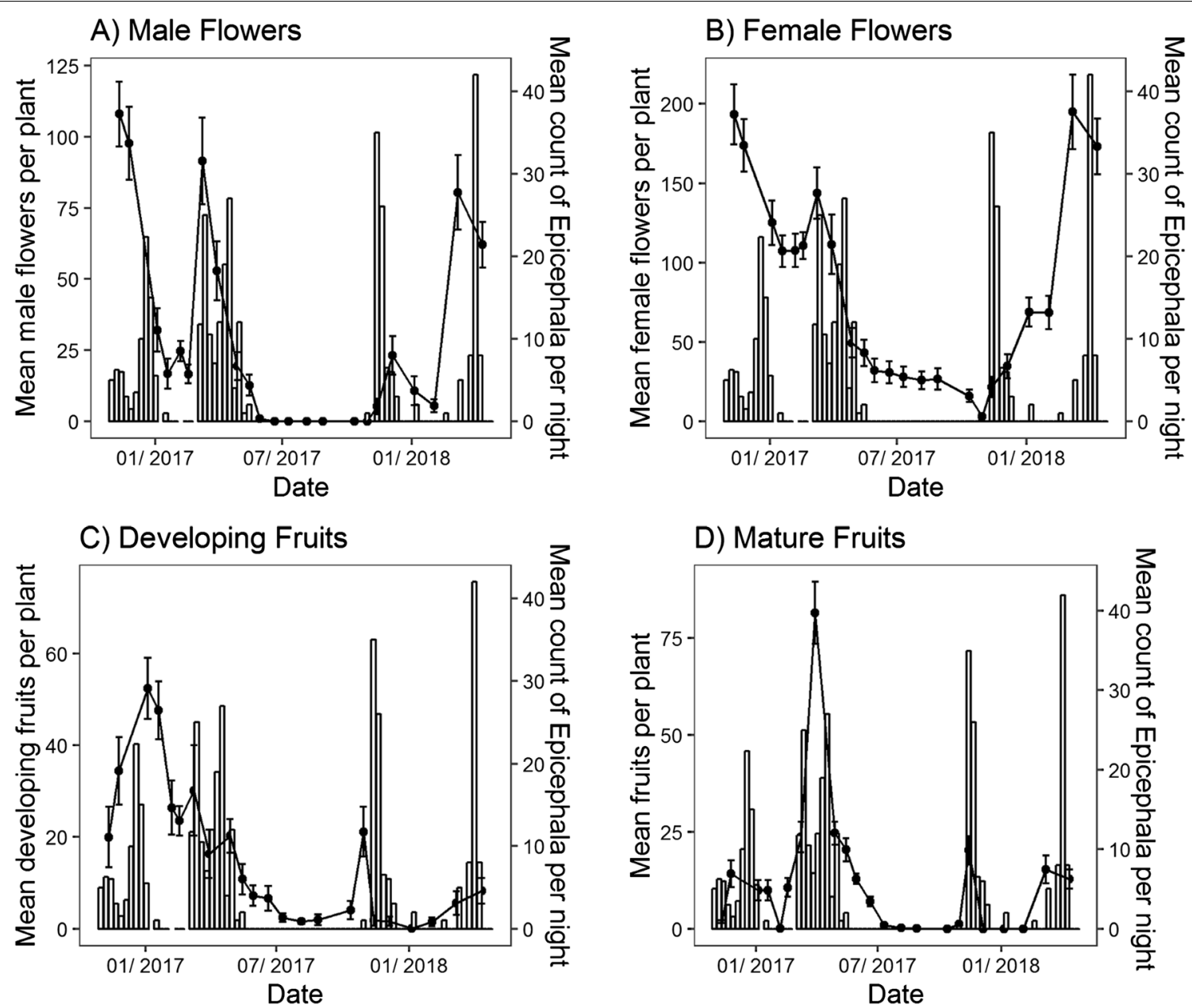

Fig. 3 Mean weekly counts of Epicephala per night (bars) alongside the mean number of $\mathbf{A}$ male flowers, $\mathbf{B}$ female flowers, $\mathbf{C}$ developing fruits, $\mathbf{D}$ mature fruits per Breynia oblongifolia plant (lines \pm SEM) at the Richmond site

Table 3 Coefficients for relationships between the number of mature fruits and temperature on Epicephala moth activity at the Richmond site

\begin{tabular}{lcccl}
\hline & $\boldsymbol{\beta}$ & $\boldsymbol{S E}$ & $\boldsymbol{z}$ & $\boldsymbol{p}$ \\
\hline Intercept & -1.3870 & 0.6177 & -2.245 & 0.02475 \\
Total mature fruits $^{\mathrm{a}}$ & 0.0013 & 0.0004 & 3.231 & 0.00123 \\
Minimum daily temp $^{\mathrm{b}}$ & 0.01962 & 0.0064 & 3.067 & 0.00216
\end{tabular}

${ }^{a}$ Total mature fruits at the time of observation

${ }^{b}$ The sum of minimum daily temperatures $14-21$ days prior to each observation

between the abundances of fruits and moths suggested that moths may diapause as eggs or young larvae within pollinated flowers, appearing as adults as fruits mature. We confirmed this by showing that many overwintering flowers contained pollen and evidence of diapausing pollinators. Our observations suggest egg diapause within dormant flowers serves a critical function of

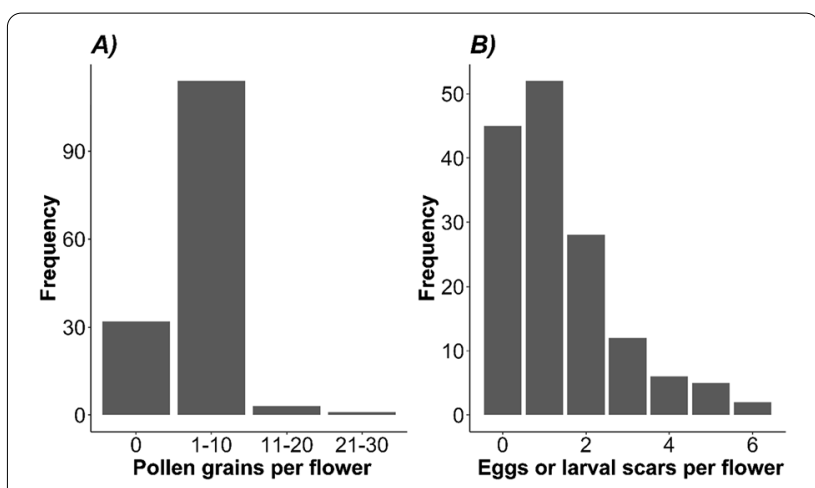

Fig. 4 Frequency distributions of $\mathbf{A}$ pollen grains and $\mathbf{B}$ eggs or larval scaring in the overwintering female flowers of Breynia oblongifolia collected during in winter at the Richmond site (July 2017) $(n=150)$ 


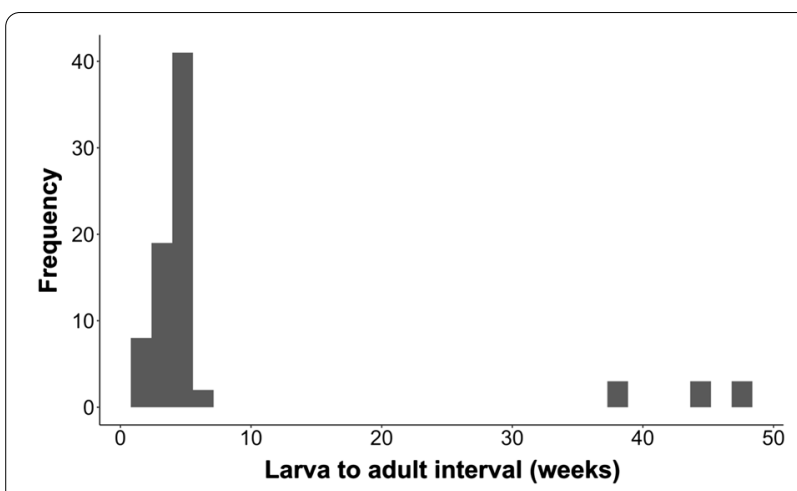

Fig. 5 Frequency distribution of the number of weeks between the emergence of Epicephala larvae and their eclosion to adults $(n=78)$ from Breynia oblongifolia fruits collected at the Richmond site.

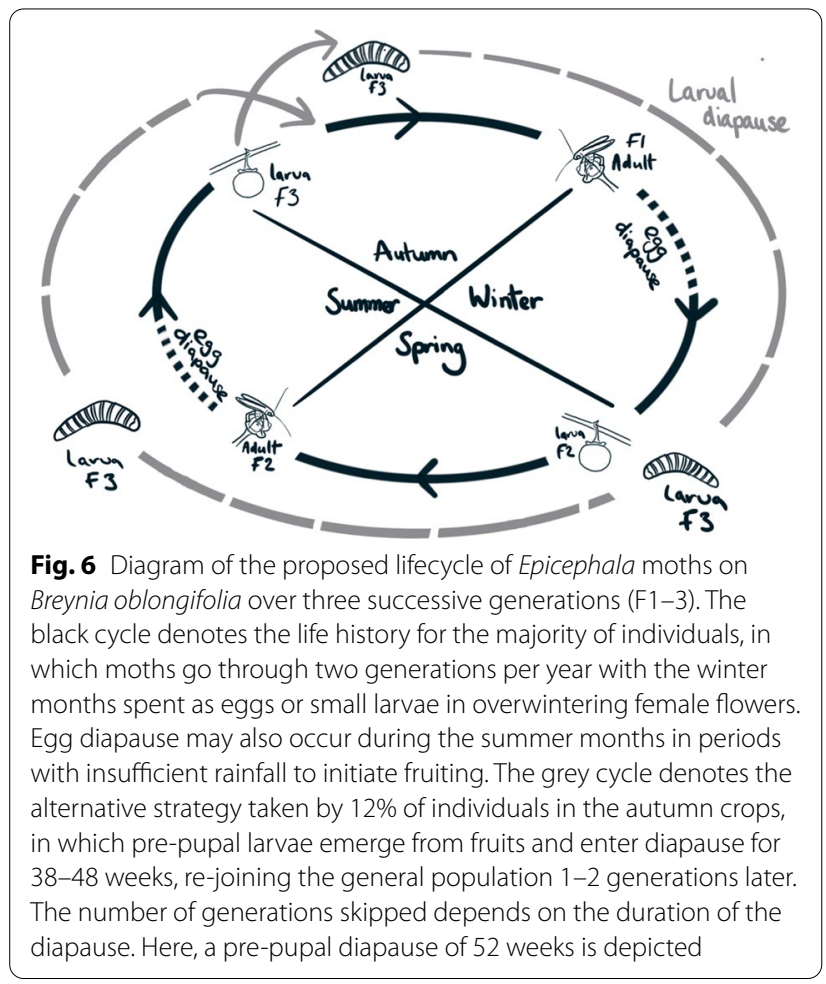

physically linking the pollinator lifecycle to host plant flowering phenology, ensuring that pollinator emergence coincides with flowering. In addition, our study of adult eclosion times also indicate that $12 \%$ of the autumn generation of Epicephala enter a pre-pupal diapause, emerging up to one year later. As such, Epicephala moths appear to use diapause at multiple stages in their lifecycle in order to track host plant phenology and mitigate against environmental unpredictability.

\section{Host plant phenology}

Inter-annual rainfall can be highly variable within Australia, even when compared to environmentally similar areas elsewhere in the world $[37,53]$. Indeed, many species of Australian plant are known to fruit and flower in response to variation in both rainfall and photoperiod $[4,5]$. In B. oblongifolia, female flowers were present all year round, but their abundance varied widely and was best predicted by rainfall and photoperiod. In this way, B. oblongifolia seems typical of many Australian plants in that its reproductive phenology is adapted to environmental unpredictability. The effect of rainfall on a plant's phenology is likely to be dependent on characteristics of the soil and surrounding landscape, as well as the frequency and intensity of previous rainfall events $[6,54$, 55]. Given that soil moisture more accurately reflects the total water available to each individual plant, we believe that it is likely that soil moisture would also be a significant predictor of flowering and fruiting phenology if included in our model.

Interestingly, our winter flower surveys show that $B$. oblongifolia frequently retains pollinated flowers over winter. Our phenological model found that B. oblongifolia sets fruit in response to rainfall. Together, these two results suggest that $B$. oblongifolia can delay fruit maturation in pollinated flowers over the winter period and potentially also through the spring and summer depending on the prevailing environmental conditions. This likely explains why only female flowers are present during the winter, as well as how some fruits began to develop in the late winter of 2017, when both Epicephala moths and male flowers were absent (Fig. 3). Indeed, our own flower bagging experiments support this explanation, with many bagged (i.e., pollinator-excluded) branches developing fruits [56]. Retaining previously pollinated flowers that can develop to fruits in response to largely unpredictable rainfall is likely to make $B$. oblongifolia less vulnerable to environmental variability, thereby reducing the risk of fruits developing during periods of drought and potential reproductive failure.

The exact mechanism that allows $B$. oblongifolia to retain pollinated flowers and then develop them to fruits months later remains unclear. Pollen can remain viable for several hours to several months depending on the species and environmental conditions [57-60]. It may be the that the pollen on the overwintering flowers of $B$. oblongifolia have yet to germinate and does so shortly before fruit development. Currently, it is not known how long the pollen of $B$. oblongifolia can remain viable under natural environmental conditions. The fruits of several important crop plants are known to arrest their 
development in response to climatic conditions, with fruit growth initiating again following pollen fertilisation $[61,62]$. As such, an alternative explanation could be that the retained pollinated flowers are already fertilised but remain in a developmental pause over winter until released by an environmental cue, such as lengthening photoperiod or increased soil moisture following rainfall. Further experimentation is required to answer these questions.

\section{Pollinator phenology}

Epicephala abundance at the Richmond field site in both the spring and summer of 2016-2017 and 2017-2018 occurred in two discrete peaks of high abundance, corresponding with similar peaks in fruit abundance (Fig. 3). Our analysis showed that the number of mature fruits was a significant predictor of Epicephala abundance. This is most likely because Epicephala moths emerge from mature fruits as larvae and then pupate to adults $[14,20]$. The appearance of fruits is therefore an important predictor of adult moth abundance, as observed in some other leaf flower species [19-21]. Although we found no statistical evidence for a relationship between rainfall and moth abundance, there is an indirect relationship between the abundance of moths and rainfall via the abundance of fruits, which is rainfall dependent. Thus, rainfall and photoperiod are critical factors in the phenology of the B. oblongifolia host plant and, by extension, its Epicephala pollinators.

Consistent with our prediction, the abundance of both male flowers and Epicephala moths were best predicted by the mean minimum temperature 14-21 days prior to each plant and pollinator survey. Lepidoptera are often phenologically synchronised with their host plant's growth stages through temperature [30-34]. As male flowers are a source of essential pollen and potentially nectar [19, 20], female Epicephala moths are likely to be under selection to synchronise their adult eclosion with the occurrence of male flowers. The fact that both male flowers and moths respond to the mean minimum temperature three weeks prior to each observation probably reflects the developmental time between the environmental trigger and appearance of mature fruits and moths. Indeed, the average time between the emergence of larvae from fruits and adult eclosion in our eclosion study was 3 to 4 weeks, strongly suggesting that temperature plays a critical role in synchronising moth and pollinator life histories.

The absence of adult moths during the winter months (June-August) and hottest summer months indicates that moths probably diapause during this stage in their lifecycle (Fig. 4). Furthermore, the close association between fruits and the abundance of adult moths suggests that these insects diapause as eggs, or possibly young larvae, within flowers that then develop to fruit. In line with our expectations, when we examined overwintering flowers, many showed scarring and boring damage consistent with Epicephala moths and their larvae [35, 36]. Although we did not survey flowers during the hottest summer months, we believe that it is very likely that moths also diapause as eggs in female flowers during this time. This is because all spring emerging larvae pupated directly to adulthood and did not enter a pre-pupal diapause. As such, spring emerging Epicephala presumably eclose, mate and lay diapausing eggs in female flowers that are present through the summer when adults are absent. Periods of egg dormancy are known in other Epicephala species [21] and many Australian Lepidoptera are also known to exhibit extended periods of egg diapause [27-29]. The larvae of some fig wasps are also known to overwinter within dormant fig flowers in temperate climates [22]. Our analysis of the phenological data has demonstrated that in B. oblongifolia, fruiting and flowering are phenologically synchronised with both fruits and new flowers appearing together. As such, egg or young larval diapause likely ensures that overwintering larvae develop and emerge at, or near, the time of flowering, creating a physical link between plant and pollinator lifecycles.

In moths, diapause can occur at both the egg and pre-pupal life history stages. Our study of the interval between larval emergence and eclosion found that $12 \%$ of the Epicephala larvae that emerged in the autumn entered a pre-pupal diapause for periods of up to 48 weeks. These long diapausing Epicephala included both species known to pollinate $B$. oblongifolia [35]. The majority of moths that emerged in the autumn pupated directly to adulthood, eclosing 3 to 4 weeks after leaving the fruits. Spring emerging Epicephala were not observed to enter an extended pre-pupal diapause, but this may reflect the lower sample size $(n=13)$. The varying lengths of pre-pupal diapause documented here may constitute a bet-hedging or risk-spreading strategy [63]. Bet-hedging strategies involve a loss of individual fitness to reduce variance in fitness over time, thereby increasing the long term (geometric) mean fitness of the genotype or lineage $[64,65]$. Such strategies are adaptive in unpredictable environments, where variance in fitness between generations is high. In our example, moths that pupate directly to adults after emerging from fruits late in the growing season may experience shortages of flowers. A bet-hedging genotype that produces multiple phenotypes (e.g., differing diapause durations) may thereby achieve greater geometric fitness over time by reducing variance in fitness between flowering seasons. Bet-hedging strategies are commonly inferred in insects, but rarely shown 
definitively [63]. This is because such strategies must be correctly distinguished from genotypic polymorphism within populations [63]. Furthermore, demonstrating that bet-hedging strategies occur requires demonstrating greater geometric fitness in bet-hedging genotypes compared to none bet-hedging genotypes. Alternatively, it is also possible to demonstrate bet-hedging by showing variation in the trait in question (e.g., diapause duration) in relation to environmental uncertainty. Bet-hedging is, therefore, challenging to demonstrate experimentally. Regardless, our work is the first to suggest the possibility of a bet-hedging strategy in a nursery pollination mutualism.

\section{Implications for the mutualism}

Since they represent independent evolutionary origins of pollination mutualism, it is interesting to compare the phenology of plants and pollinators in the fig, Yucca, and leaf flower mutualisms. Based on available data, it would seem that, at the population level, the flowers of both fig trees and leaf flowers are generally present throughout the year [18-21, 24, 25]. However, as this study and others have demonstrated [21], flowers may be present but dormant for part of that time. In at least one temperate fig species, overwintering flowers act as refuges for fig wasp pollinators through the winter months [22]. In B. oblongifolia, and possibly other leaf flower plants, the majority of plants bear female flowers year-round, with low numbers also present during the winter. Year round flowering may thereby promote stable populations of Epicephala moths by providing a refuge for pollinators during periods when plants are not growing fruits or new flowers. This could explain why some B. oblongifolia plants maintained female flowers during periods of obvious drought stress in the unusually dry winter of 2017. Indeed, our observation that these pollinated and pollinator-containing flowers were maintained at the expense of leaf tissues suggests a high fitness value to the host plants. In the Yucca-yucca moth OPM, pollinators diapause as pre-pupal larvae in the soil around their host plants and may wait several years between the appearance of flowers [11]. The ability of yucca moths to diapause for multiple years between flowering events probably also promotes the stability of pollinator populations. Our study has found that both year-round flower provision and pre-pupal diapause occur in at least some leaf flower plants, showing similarities with both the Yucca and fig mutualisms.

Egg diapause in Epicephala may have other important implications for the mutualism. Overwintering larvae or eggs are likely to suffer moderate levels of mortality during diapause [66, 67]. This increased mortality may benefit the plant by reducing the number of seeds that are consumed by pollinators. Overwintering mortality could help to explain the large proportion of B. oblongifolia fruits (10-30\%) that do not contain Epicephala larvae [36]. Fruits that do not contain pollinators are generally more frequent in crops collected in the spring and contribute a high proportion of the intact seeds produced across $B$. oblongifolia populations [36]. As such, egg diapause mortality may be an important factor in reducing seed destruction by pollinating seed herbivores, thereby helping to maintain the mutualism in the face of competing interests between mutualists.

\section{Conclusions}

Epicephala moths appear to use diapause at multiple stages in their lifecycle in order to survive through periods of variable plant phenology. Furthermore, moth abundance is predicted by the same environmental variables as male flowers, suggesting that moths track flowering through temperature. These adaptations may thereby mitigate against unpredictability in the timing of fruiting and flowering because of variable rainfall. This is the first study of how Epicephala moths track host plant phenology and avoid potentially disastrous phenological mismatches. How widespread egg and pre-pupal diapause are within Epicephala moths remains to be seen. Such traits may have important implications for both the evolutionary stability of these mutualisms and their rapid diversification.

\section{Supplementary Information}

The online version contains supplementary material available at https://doi. org/10.1186/s12862-021-01889-4.

Additional file1 (PNG 215 KB)

\section{Acknowledgements}

We wish to thank to the technical, management and academic staff at the EucFACE facility at Western Sydney University for facilitating and aiding fieldwork at the site. EucFACE is supported by the Australian Commonwealth Government in collaboration with Western Sydney University. EucFACE was built as an initiative of the Australian Government as part of the Nationbuilding Economic Stimulus Package. We wish to thank Laura Brettell, Lisa Vella and Giles Ross for their assistance with pollinator surveys. We also wish to thank Jeff Chieppa for his very helpful advice on data analysis. Finally, we wish to thank Jeff Ollerton and Anne Gaskett for their inciteful comments on this manuscript as part of JF's PhD thesis [68].

\section{Authors' contributions}

JF acquired the funding, designed the study, collected the data, analysed the results and wrote the manuscript. SP designed the study and reviewed the manuscript. JW designed the study and reviewed the manuscript. JC acquired the funding, designed the study and wrote the manuscript. All authors read and approved the final manuscript. 


\section{Funding}

JF thanks Western Sydney University for an International PhD Scholarship that covered student fees, research consumables and a maintenance stipend. JF would also like to thank Horticultural Innovation Australia, who supported him during manuscript preparation as part of the national collaborative project on Managing Flies for Crop Pollination (Grant No. PH16002) with the Department of Primary Industries and Regional Development (DPIRD), Western Sydney University, University of New England, The University of Western Australia and SeedPurity Pty Ltd.

\section{Availability of data and materials}

The datasets supporting the conclusions of this article have been made publicly and permanently available in the Figshare online repository under the following DOls: winter flower surveys https://doi.org/10.6084/m9.figsh are.14623872.v1, flowering and fruit phenology, https://doi.org/10.6084/m9. figshare.14623641.v3, pollinator phenology, https://doi.org/10.6084/m9.figsh are.14623563.v3,and pre-pupal diapause https://doi.org/10.6084/m9.figshare. 14625531.v1.

\section{Declarations}

\section{Ethics approval and consent to participate}

Not applicable.

\section{Consent for publication}

Not applicable.

\section{Competing interests}

The authors declare that they have no competing interests.

Received: 19 May 2021 Accepted: 19 July 2021

Published online: 24 August 2021

\section{References}

1. Armstrong JB, Takimoto G, Schindler DE, Hayes MM, Kauffman MJ. Resource waves: phenological diversity enhances foraging opportunities for mobile consumers. Ecology. 2016;97:1099-112. https://doi.org/10. 1890/15-0554.1.

2. Rivrud IM, Sivertsen TR, Mysterud A, Åhman B, Støen O-G, Skarin A. Reindeer green-wave surfing constrained by predators. Ecosphere. 2018;9: e02210. https://doi.org/10.1002/ecs2.2210.

3. Deacy W, Leacock W, Armstrong JB, Stanford JA. Kodiak brown bears surf the salmon red wave: direct evidence from GPS collared individuals. Ecology. 2016;97:1091-8. https://doi.org/10.1890/15-1060.1.

4. Friedel M, Nelson D, Sparrow A, Kinloch J, Maconochie J. Flowering and fruiting of arid zone species of Acacia in central Australia. J Arid Environ. 1994;27:221-39. https://doi.org/10.1006/JARE.1994.1060.

5. Davies SJJF. Studies of the flowering season and fruit production of some arid zone shrubs and trees in western Australia. J Ecol. 1976;64:665. https://doi.org/10.2307/2258777.

6. Jolly WM, Running SW. Effects of precipitation and soil water potential on drought deciduous phenology in the Kalahari. Glob Chang Biol. 2004;10:303-8. https://doi.org/10.1046/j.1365-2486.2003.00701.x.

7. Encinas-Viso F, Revilla TA, Etienne RS. Phenology drives mutualistic network structure and diversity. Ecol Lett. 2012;15:198-208. https://doi.org/ 10.1111/j.1461-0248.2011.01726.x.

8. Hembry DH, Althoff DM. Diversification and coevolution in brood pollination mutualisms: windows into the role of biotic interactions in generating biological diversity. Am J Bot. 2016;103:1783-92. https://doi.org/10. 3732/ajb.1600056.

9. Kato M, Kawakita A, editors. Obligate pollination mutualism. 1st ed. Tokyo: Springer; 2017

10. Cook JM, Rasplus J-Y. Mutualists with attitude: coevolving fig wasps and figs. Trends Ecol Evol. 2003;18:241-8.

11. Pellmyr O. Yuccas, yucca moths, and coevolution: a review. Ann Missouri Bot Gard. 2003;90:35-55.
12. Thompson JN, Pellmyr O. Mutualism with pollinating seed parasites amid co-pollinators: constraints on specialization. Ecology. 1992;73:1780-91. https://doi.org/10.2307/1940029.

13. Kawakita A. Evolution of obligate pollination mutualism in the tribe Phyllantheae (Phyllanthaceae). Plant Species Biol. 2010;25:3-19.

14. Kato M, Takimura A, Kawakita A. An obligate pollination mutualism and reciprocal diversification in the tree genus Glochidion (Euphorbiaceae). Proc Natl Acad Sci USA. 2003;100:1.

15. Kawakita A, Kato M. Repeated independent evolution of obligate pollination mutualism in the Phyllantheae-Epicephala association. Proc Biol Sci. 2009;276:417-26.

16. Kawakita A, Sato AAW, Salazar JRL, Kato M. Leafflower-leafflower moth mutualism in the Neotropics: Successful transoceanic dispersal from the Old World to the New World by actively-pollinating leafflower moths. PLOS ONE. 2019;14: e0210727. https://doi.org/10.1371/journal.pone. 0210727.

17. Henderson E, Missen M, Zalucki J. To pupate or not to pupate: A case study of an obligate pollination mutualism in Glochidion ferdinandi (Phyllanthaceae) and Epicephala colymbetella (Gracillariidae). Aust J Bot. 2019;67:473-9. https://doi.org/10.1071/BT18142.

18. Bronstein JL, Gouyon P-H, Gliddon C, Kjellberg F, Michaloud G. The ecological consequences of flowering asynchrony in monoecious figs: a simulation study. Ecology. 1990;71:2145-56. https://doi.org/10.2307/ 1938628.

19. Zhang J, Wang S, Li H, Hu B, Yang X, Wang Z. Diffuse coevolution between two Epicephala species (Gracillariidae) and two Breynia species (Phyllanthaceae). PLoS ONE. 2012;7: e41657. https://doi.org/10.1371/journal. pone.0041657.

20. Kawakita A, Kato M. Obligate pollination mutualism in Breynia (Phyllanthaceae): further documentation of pollination mutualism involving Epicephala moths (Gracillariidae). Am J Bot. 2004;91:1319-25.

21. Luo SX, Yao G, Wang Z, Zhang D, Hembry DH. A novel, enigmatic basal leafflower moth lineage pollinating a derived leafflower host illustrates the dynamics of host shifts, partner replacement, and apparent coadaptation in intimate mutualisms. Am Nat. 2017;189:422-35. https://doi.org/ 10.1086/690623.

22. Kjellberg F, Gouyon PH, Ibrahim M, Raymond M, Valdeyron G. The stability of the symbiosis between dioecious figs and their pollinators: a study of Ficus carica L. and Blastophaga psenes L. Evolution (NY). 1987;41:693-704. https://doi.org/10.1111/j.1558-5646.1987.tb05846.x.

23. Chiang YP, Bain A, Wu WJ, Chou LS. Adaptive phenology of Ficus subpisocarpa and Ficus caulocarpa in Taipei, Taiwan. Acta Oecologica. 2018;90:35-45.

24. Pereira RAS, Rodrigues E, Menezes ADO. Phenological patterns of Ficus citrifolia (Moraceae) in a seasonal humid-subtropical region in southern Brazil. Plant Ecol. 2007;188:265-75. https://doi.org/10.1007/ s11258-006-9161-0

25. Peng YQ, Compton SG, Yang DR. The reproductive success of Ficus altissima and its pollinator in a strongly seasonal environment: Xishuangbanna Southwestern China. Plant Ecol. 2010;209:227-36. https://doi.org/ 10.1007/s11258-009-9690-4.

26. Jia X-C, Dan Y, Zhang Y, Chen Y-Z. Direct evidence for the cycling of fig wasps within one male fig tree. Nord J Bot. 2007;25:119-24. https://doi. org/10.1111/j.0107-055X.2007.00021_23.x.

27. Sands DPA, New TR. Irregular diapause, apparency and evaluating conservation status: anomalies from the Australian butterflies. J Insect Conserv. 2008;12:81-5. https://doi.org/10.1007/s10841-006-9056-3.

28. Kemp D. Reproductive seasonality in the tropical butterfly Hypolimnas bolina (Lepidoptera: Nymphalidae) in northern Australia. J Trop Ecol. 2001;17:483-94. https://doi.org/10.1017/S0266467401001365.

29. Denlinger DL. Dormancy in tropical insects. Annu Rev Entomol. 1986;31:239-64. https://doi.org/10.1146/annurev.en.31.010186.001323.

30. Posledovich D, Toftegaard T, Wiklund C, Ehrlén J, Gotthard K. Phenological synchrony between a butterfly and its host plants: experimental test of effects of spring temperature. J Anim Ecol. 2018;87:150-61. https://doi. org/10.1111/1365-2656.12770.

31. Fuentealba A, Pureswaran D, Bauce É, Despland E. How does synchrony with host plant affect the performance of an outbreaking insect defoliator? Oecologia. 2017;184:847-57. https://doi.org/10.1007/ s00442-017-3914-4. 
32. Phillimore AB, Stålhandske S, Smithers RJ, Bernard R. Dissecting the contributions of plasticity and local adaptation to the phenology of a butterfly and its host plants. Am Nat. 2012;180:655-70. https://doi.org/10. 1086/667893

33. Leland Russell F, Louda SM. Phenological synchrony affects interaction strength of an exotic weevil with Platte thistle, a native host plant. Oecologia. 2004;139:525-34. https://doi.org/10.1007/s00442-004-1543-1.

34. van Asch M, Visser ME. Phenology of forest caterpillars and their host trees: the importance of synchrony. Annu Rev Entomol. 2007;52:37-55. https://doi.org/10.1146/annurev.ento.52.110405.091418.

35. Finch JTD, Power SA, Welbergen JA, Cook JM. Two's company, three's a crowd: co-occurring pollinators and parasite species in Breynia oblongifolia (Phyllanthaceae). BMC Evol Biol. 2018;18:193. https://doi.org/10.1186/ s12862-018-1314-y.

36. Finch JTD, Power SA, Welbergen JA, Cook JM. A non-pollinating moth inflicts higher seed predation than two co-pollinators in an obligate pollination mutualism. Ecol Entomol. 2019. https://doi.org/10.1111/een. 12754.

37. Risbey JS, Pook MJ, McIntosh PC, Wheeler MC, Hendon HH, Risbey JS, et al. On the remote drivers of rainfall variability in Australia. Mon Weather Rev. 2009;137:3233-53. https://doi.org/10.1175/2009MWR2861.1.

38. Wang $\mathrm{G}$, Hendon $\mathrm{HH}$. Sensitivity of Australian rainfall to inter-El Niño variations. J Clim. 2007;20:4211-26. https://doi.org/10.1175/JCLI4228.1.

39. Ashok K, Guan Z, Yamagata T. Influence of the Indian Ocean Dipole on the Australian winter rainfall. Geophys Res Lett. 2003. https://doi.org/10. 1029/2003GL017926.

40. Atlas of Living Australia. Atlas of Living Australia Website. 2018. https:// www.ala.org.au/. Accessed 27 Jul 2018.

41. Kawakita A, Kato M. Revision of the Japanese species of Epicephala Meyrick with descriptions of seven new species (Lepidoptera, Gracillariidae). Zookeys. 2016. https://doi.org/10.3897/zookeys.568.6721.

42. Zhang J, Hu B, Wang S, Li H. Six new species of Epicephala Meyrick, 1880 (Lepidoptera: Gracillariidae) associated with Phyllanthaceae plants. Zootaxa. 2012;3275:43-54.

43. RStudio Team. RStudio: Integrated Development for R. 2020.

44. R Core Team. R: A language and environment for statistical computing. 2021. http://www.r-project.org/.

45. Bureau of Meteorology: Bureau of Meteorology. 2018. http://www.bom. gov.au/. Accessed 12 Aug 2018

46. Friedel M, Nelson D, Sparrow A, Kinloch J, Maconochie J. What induces central Australian arid zone trees and shrubs to flower and fruit? Aust J Bot. 1993:41:307. https://doi.org/10.1071/BT9930307.

47. Warton DI. Many zeros does not mean zero inflation: comparing the goodness-of-fit of parametric models to multivariate abundance data. Environmetrics. 2005;16:275-89. https://doi.org/10.1002/env.702.

48. Bates D, Mächler M, Bolker B, Walker S. Fitting linear mixed-effects models using Ime4. J Stat Softw. 2015;67:1-48. https://doi.org/10.18637/jss.v067. i01.

49. Barton K. Mu-MIn: Multi-model inference. 2009. http://r-forge.r-project. org/projects/mumin/.

50. Pinheiro JC, Bates DM. Mixed-effects models in S and S-PLUS. Springer; 2000.

51. Bolker BM, Brooks ME, Clark CJ, Geange SW, Poulsen JR, Stevens MHH, et al. Generalized linear mixed models: a practical guide for ecology and evolution. Trends Ecol Evol. 2009;24:127-35. https://doi.org/10.1016/j. tree.2008.10.008.
52. Venables WN, Ripley BD, Venables WN. Modern applied statistics with S. New York: Springer; 2002.

53. Nicholls N, Drosdowsky W, Lavery B. Australian rainfall variability and change. Weather. 1997;52:66-72. https://doi.org/10.1002/j.1477-8696. 1997.tb06274.x.

54. Reynolds JF, Kemp PR, Ogle K, Fernández RJ. Modifying the 'pulse-reserve' paradigm for deserts of North America: precipitation pulses, soil water, and plant responses. Oecologia. 2004;141:194-210. https://doi.org/10. 1007/s00442-004-1524-4.

55. Borchert R. Soil and stem water storage determine phenology and distribution of tropical dry forest trees. Ecology. 1994;75:1437-49. https://doi. org/10.2307/1937467.

56. Finch J, Power S, Welbergen J, Cook J. Testing for apomixis in an obligate pollination mutualism. J Pollin Ecol. 2021. https://doi.org/10.26786/19207603(2021)644

57. Johri BM, Vasil IK. Physiology of pollen. Bot Rev. 1961;27:323-68.

58. Ramsey M, Vaughton G. Self-incompatibility, protandry, pollen production and pollen longevity in Banksia menziesii. Aust J Bot. 1991;39:497-504

59. Luna SV, Figueroa MJ, Baltazar MB, Gomez LR, Townsend R, Schoper JB. Maize pollen longevity and distance isolation requirements for effective pollen control. Crop Sci. 2001;41:1551-7.

60. Báez P, Riveros M, Lehnebach C. Viability and longevity of pollen of Nothofagus species in south Chile. New Zeal J Bot. 2002:40:671-8.

61. Wang H, Schauer N, Usadel B, Frasse P, Zouine M, Hernould M, et al. Regulatory features underlying pollination-dependent and-independent tomato fruit set revealed by transcript and primary metabolite profiling. Plant Cell. 2009;21:1428-52.

62. Malladi A, Klima JL. Expression profiling of cell cycle genes reveals key facilitators of cell production during carpel development, fruit set, and fruit growth in apple (Malus3domestica Borkh.). J Exp Bot. 2011;62:20519. https://doi.org/10.1093/jxb/erq258.

63. Hopper KR. Risk-spreading and bet-hedging in insect population biology. Annu Rev Entomol. 1999;44:535-60. https://doi.org/10.1146/annurev. ento.44.1.535.

64. Seger J, Brockmann HJ. What is bet-hedging? In: Harvey PHPL, editor. Oxford surveys in evolutionary biology. Oxford: Oxford University Press; 1987. p. 182-211.

65. Haaland TR, Wright J, Ratikainen II. Bet-hedging across generations can affect the evolution of variance-sensitive strategies within generations. Proc R Soc B Biol Sci. 2019. https://doi.org/10.1098/rspb.2019.2070.

66. Elverum F, Johansen T, Nilssen A. Life history, egg cold hardiness and diapause of Argyresthia retinella (Lepidoptera: Yponomeutidae). Nor J Entomol. 2003:50:43-53.

67. Régnière J, Duval P. Overwintering mortality of spruce budworm, Choristoneura fumiferana (Clem.) (Lepidoptera: Tortricidae), populations under field conditions. Can Entomol. 1998;130:13-26. https://doi.org/10.4039/ Ent13013-1.

68. Finch JTD. Dynamics of an obligate pollination mutualism in the Australian Phyllanthaceae. PhD thesis, Western Sydney University, Australia. PhD Thesis, Western Sydney University, Australia; 2018.

\section{Publisher's Note}

Springer Nature remains neutral with regard to jurisdictional claims in published maps and institutional affiliations. 